\title{
EXCEPCIÓN AL CONSENTIMIENTO INFORMADO EN LA LEY GENERAL PENITENCIARIA DE ESPAÑA Y LAS INTERVENCIONES MÉDICAS FORZOSAS EN HUELGAS DE HAMBRE LLEVADAS A CABO POR ENCARCELADOS
}

\author{
SANDRO LUIS BRITO NOVAIS \\ Doutorando em Direito Civil na Universidad de La Coruña \\ (Espanha). Advogado. \\ sandronovais@hotmail.com
}

Sumário: 1. Introducción; 2. La evolución de la relación médicopaciente (del principio paternalista a la autodeterminación del paciente); 3. El consentimiento informado; 4. Excepciones al consentimiento informado; 5 . Excepción al consentimiento estipulada en la Ley General Penitenciaria de España; 6. Conclusión.

\begin{abstract}
Resumen: El presente artículo tiene por objetivo, además de esbozar un panorama sobre la figura jurídica del consentimiento informado y de sus excepciones, discutir la interpretación del Tribunal Constitucional español de la excepción al consentimiento prevista en la Ley Penitenciaria española, específicamente en los casos de huelgas de hambre llevadas a cabo por presidiarios acusados de terrorismo. A partir de revisión bibliográfica, se ha analizado el tenor de las sentencias del TC, las cuales, contrariando la regla general que indica que se hace necesario el consentimiento para que se aplique un procedimiento médico, autorizan la alimentación forzosa de reclusos en riesgo de vida.
\end{abstract}

Palabras clave: Consentimiento informado. Huelga. Hambre.

\section{INTRODUCCIÓN}

La intervención médica para alimentar forzosamente, a través de una sonda, a un detento perteneciente a la organización terrorista ETA, es decir, prescindiendo de su consentimiento, en una huelga de hambre de 112 días, ha sido el leit motiv de este trabajo. Aunque este no haya sido el primer caso con estas implicaciones -hubo otros anteriores en los cuales estaban involucrados integrantes de otra banda terrorista, 
denominada GRAPO-, la figura mediática de su personaje principal ha hecho que el asunto volviera al orden del día. Antes de adentrarse el tema, cumple advertir que la cuestión aquí analizada no está centrada en las implicaciones políticas de la decisión de poner en libertad al recluso, sino que tiene foco exclusivo en el análisis del límite al derecho de los presos al consentimiento informado impuesto por el Tribunal Constitucional desde su interpretación de la Ley General Penitenciaria de España.

Al principio del año 2005, cuando los periódicos desvelan que José Ignacio de Juana (De Juana Chaos), "un etarra condenado por 25 asesinatos y penado con casi 3.000 años de cárcel va a salir en libertad de forma inminente tras haber cumplido sólo 18 años de cárcel", hubo una oleada de protestas, por lo que la Audiencia Nacional de España terminó por imputarle más dos delitos, condenándole por las acusaciones de amenazas terroristas y de pertenencia a banda armada, a raíz de dos artículos publicados con su firma en el periódico Gara.

Debido al aumento de su condena, el recluso inició una huelga de hambre el 7 de agosto en demanda de su puesta en libertad tras cumplir 18 años en la cárcel, como antes esperado. El preso, que tenía el peso habitual de $86 \mathrm{kilos}$, llega a tener 63. Desde entonces, se niega a colaborar con los médicos responsables, los cuales tienen que pesarlo, hacer los análisis y, incluso, tomarle la tensión a la fuerza. El 11 de diciembre de 2006, ante el grave cuadro de salud -el recluso ha llegado a los 57 kilos-, los facultativos, indiferentes a la ausencia de consentimiento del paciente, es más, sin hacer caso a su resignación en seguir con la huelga de hambre hasta la muerte, pasan a alimentarlo por sonda nasogástrica.

El interés de este trabajo radica, pues, en abordar la excepción prevista en la Ley general penitenciaria de España, la cual ha servido para fundar varias decisiones del Tribunal Constitucional de España que apuntan para una peculiar y controvertida relación de sujeción existente entre los presos y el Estado, capaz de suprimir derechos de los reclusos, como el derecho a consentir, o no, sobre los tratamientos clínicos que les sean prescritos.

\section{LA EVOLUCIÓN DE LA RELACIÓN MÉDICO-PACIENTE (DEL PRINCIPIO PATERNALISTA A LA AUTODETERMINACIÓN DEL PACIENTE)}

La evolución de los paradigmas concernientes a la relación médico-paciente viene a remolque de la relevancia que ha adquirido el derecho a la salud, lo cual constituye un elemento básico del desarrollo de todo ser humano y se encuentra estrechamente vinculado a los derechos fundamentales a la dignidad y al libre desarrollo de la personalidad, así como el derecho a la integridad física y moral, con el derecho a la libertad ideológica y religiosa y con el derecho a la intimidad. En los últimos años, se verifica que la mayor relevancia y el desarrollo del principio de protección de la salud han alzado los derechos de los pacientes a la categoría de eje básico de las relaciones 
clínico-asistenciales, por eso, se ha dicho que la llamada relación clínica está adquiriendo una nueva configuración en los momentos actuales ${ }^{1}$. No por acaso, el constitucionalismo moderno refleja, en un proceso imparable de internacionalización de los derechos humanos ${ }^{2}$, la aceptación de que las garantías a la salud significan, ante todo, posibilitar el libre e integral desarrollo de la persona. Tampoco la comunidad internacional ha dejado de acompañar esta evolución; las Naciones Unidas, UNESCO y la Organización Mundial de la Salud, han formulado declaraciones o normas sobre diversos aspectos relativos a la salud que se han completado en el ámbito europeo por la Unión Europea y por el Consejo de Europa.

Pero no siempre ha sido así, ya que no hace mucho tiempo los presupuestos de la relación clínica giraban alrededor del médico como elemento fundamental de la misma, con ninguna o poca relevancia del enfermo. Esta forma de comprender la alianza terapéutica venía dictada por la tradición; respondía, por tanto, a una configuración histórica de muchos siglos y estaba adaptada a las necesidades y al entorno de la sociedad $^{3}$. En términos filosóficos, se consideraba, en un periodo anterior, que el médico restauraba el equilibrio de la naturaleza al curar el paciente y que, además, respondía al conocimiento que tenían los profesionales y que estaban en una situación de preeminencia a la hora de tomar decisiones en busca del bienestar del enfermo. La relación médicopaciente, pues, se encontraba anclada en el principio paternalista o de la beneficencia, lo cual presuponía la verticalidad entre los sujetos partícipes, o sea, la sumisión existente hacía con que el paciente fuese considerado una persona débil, sin capacidad de discernir $\mathrm{y}$, por consiguiente, de decidir sobre cualquier aspecto de su tratamiento. De esta manera, el médico era quien tenia conocimiento exacto y exclusivo sobre lo que hacer con el paciente, y siempre lo haría en busca de lo mejor para el enfermo, aunque éste nada supiera sobre su estado clínico, sobre las alternativas curativas disponibles y, notadamente, sin ningún conocimiento de los riesgos implicados.

La persona pendiente de la intervención sanitaria no debería hacer nada más que condicionarse a los designios del médico Era esa, por lo tanto, la tónica de la relación entre el médico y el paciente cuando prevalecía, todavía, el principio paternalista en la medicina, lo cual hacia con que se suprimiese la voluntad del paciente a favor del buen actuar médico y que - retornando más una vez a sus orígenes históricos - fue establecido por la tradición hipocrática y trasladado, después, a normas éticas y deontológicas. Se pensaba incluso que el consentimiento era irrelevante y que el médico

\footnotetext{
${ }^{1}$ SÁnChEZ-CARO, J.: "La relación médico-paciente en el siglo XXI" in Bioética, religión y derecho (actas del curso de verano de la Universidad Autónoma de Madrid celebrado en Miraflores de la Sierra del 14 al 16 de julio de 2005). Madrid, Fundación Universitaria Española, 2005, p. 13.

${ }^{2}$ Guerrero Zaplana, J.: El consentimiento informado. Su valoración en la jurisprudencia. Valladolid, Ed. Lex Nova, 2004, p. 10.

${ }^{3}$ SÁnchez-Caro, J.: op. cit., p. 20.
} 
debía intervenir aun con la oposición del paciente porque estaba de por medio el deber ético y moral del médico de salvar la vida de las personas ${ }^{4}$. Así, se tenía en cuenta que lo realmente importante es esta relación era la curación del enfermo, mismo que contra su voluntad, o peor, aunque ello de nada supiera y solamente entregase su vida, su integridad física y psicológica a los médicos.

El abandono del principio paternalista ha sido gradual, ya que la adopción de éste significa un gradual cambio de paradigma hacia la autonomía del paciente, etapa en que se supone, dentro de las relaciones clínicas, el reconocimiento del paciente en su individualidad, en la cual se reconoce el enfermo como un ser pleno y capaz de, desde una relación en la que él y el médico ocupan un plano homólogo, decidir libremente sobre el procedimiento clínico o quirúrgico a que quiere someterse. Aquí, en un modelo horizontal, el paciente adquiere mayor proyección en la relación clínica y pasa a ser más responsable sobre el tratamiento, en la medida que la idea de resignación y pasividad se desvanecen. Seguramente, la obligatoriedad, salvo rigurosas y justificadas excepciones previstas en ley, de respetar la libre elección del tratamiento médico por parte del paciente sobresaldrá en el ámbito sanitario. Sin embargo, este nuevo entramado de relaciones, que se construye a partir del reconocimiento pleno de la autonomía del paciente, de su derecho al libre desarrollo de su personalidad, de su derecho a la salud y a la integridad física y psicológica, desde la aceptación del paciente como un ser dotado de racionalidad y libertad, aún encuentra resistencia. De ahí, la afirmación de Hоттогs y Missa ${ }^{5}$ en la edición traducida para la lengua gallega de la Nouvelle encyclopédie de bioéthique, "o dilema ético subxacente na cuestión do consentimento reside na tensión entre o principio de autonomía do paciente e o principio de beneficencia do médico".

\section{EL CONSENTIMIENTO INFORMADO}

A partir del reconocimiento del principio de la autonomía en el seno de las relaciones médicas, era inevitable dotar el paciente de un instrumento capaz de garantizar el pleno respeto a su voluntad. Entonces, se logró la consagración del denominado consentimiento informado. De ahí que se ha subrayado en la exposición de motivos de la Ley 41/2002 que "la importancia que tienen los derechos de los pacientes como eje básico de las relaciones clínico-asistenciales se pone de manifiesto al constatar el interés que han demostrado por los mismos casi todas las organizaciones internacionales

${ }^{4}$ Cantero Martínez, J.: La autonomía del paciente: del consentimiento informado al testamento vital. Albacete, Editorial Bomarzo, 2005, p. 7.

${ }^{5}$ Hоттог, G. et alli: Nova enciclopedia de bioética. Santiago de Compostela, Servizo de Publicacións e Intercambio Científico, 2005, p. 264. 
con competencia en la materia. Ya desde el fin de la Segunda Guerra Mundial, organizaciones como Naciones Unidas, UNESCO o la Organización Mundial de la Salud, o, más recientemente, la Unión Europea o el Consejo de Europa, entre muchas otras, han impulsado declaraciones o, en algún caso, han promulgado normas jurídicas sobre aspectos genéricos o específicos relacionados con esta cuestión".

Se puede decir, a priori, que el consentimiento informado depende de la información anticipada, pues solamente si se dispone de información médica adecuada se puede elegir libremente entre las distintas vertientes curativas, y ello aunque su elección no sea la que más convenga a su salud o la que mejor satisfaga los deseos de su médico ${ }^{6}$. Hoy, por tanto, al buscarse el verdadero contenido sustantivo de lo que llamamos "consentimiento informado", vemos que se trata de un proceso deliberativo -la denominación se justifica por la necesidad de información continuada durante todo el procedimiento curativo hasta que sea recabado el consentimiento - cuyo resultado es una toma de decisiones conjunta entre paciente y médico. El médico ya no decide más por el paciente, como hacía en el paternalismo, pero el paciente tampoco debe decidir sin el médico sino junto al médico y con el médico, pues una de las mayores tragedias de la teoría del consentimiento informado es haber transmitido la idea de que lo fundamental era satisfacer el "derecho del paciente a ser dejado solo" frente a las decisiones sanitarias, como bien ha subrayado PABLO SIMÓN ${ }^{7}$. Así, desde el adviento del concepto de consentimiento informado se tiene en cuenta que la decisión de cómo resolverse las situaciones clínicas que se presenten se encuentra, al fin y al cabo, en las manos del paciente, pero no sin antes facilitarle toda información útil para la toma de decisión, le siendo facultado abstenerse de recibir cualquiera información sobre su estado, hipótesis en que prestará un consentimiento ignorante. Por lo tanto, la ética médica parte de que el ser humano es capaz de autorreflexión, ya que tiene una voluntad libre, siendo la consecuencia inevitable el que habitualmente haya que dejar de lado las consideraciones utilitaristas para tener en cuenta las que atañen a la autonomía del individuo y a la justicia, que se deriva de los intereses de la sociedad ${ }^{8}$.

Abundan los conceptos doctrinales de "consentimiento", así que, debido a la limitación de espacio, apenas algunos serán puestos aquí. El término en boga es apuntado como "el acuerdo de dos voluntades" (CERRILlo, F.: Nueva Enciclopedia Jurídica. Tomo V, Barcelona, Ed. Francisco Seix, 1985, p. 80), o encuentra definición en “un

${ }^{6}$ SÁnchez Caro, J.: “Autonomía y derecho a la salud: límites”. Revista Todo Hospital, n 42, diciembre de 1997, p. 14.

${ }^{7}$ Simón, P.: El consentimiento informado. Historia, teoría y práctica. Madrid, ed. Triacastela, 2000, pp. $249 / 252$.

${ }^{8}$ SÁNCHEZ-CARO, J.: "La relación médico-paciente en el siglo XXI" in Bioética, religión y derecho (actas del curso de verano de la Universidad Autónoma de Madrid celebrado en Miraflores de la Sierra del 14 al 16 de julio de 2005). Madrid, Fundación Universitaria Española, 2005, pp. 19/20. 
acto espiritual que significa la coincidencia de voluntades en un objetivo que, desde este mismo momento, es compartido" (Corbella Duch, J.: Manual de Derecho sanitario. Barcelona, Ed. Atelier, 2006, p. 116), o, aún, que tal término expresa "la coincidencia de las voluntades de varias personas" (Hattenhauer, H.: Conceptos fundamentales del Derecho Civil. Trad. G. Hernández. Barcelona, Ed. Ariel, 1987, p. 68). Aunque tales definiciones sean correctas, puede que resulten insuficientes. Así, se recurre a la semántica, la cual nos aporta más elementos para configurar una mejor definición del término en foco; el Diccionario de la Real Academia Española (DRAE) $)^{9}$, apunta que "consentimiento" es "acción o efecto de consentir", más adelante, aclara que el vocablo "consentir" consiste en "permitir una cosa o condescender en que se haga". Ya en el Diccionario Señas ${ }^{10}$, el término "consentimiento" figura como "autorización o aprobación; permiso para hacer una cosa", y el vocablo "consentir", por su turno, está relacionado al "permiso que se concede para que se haga una cosa o, además, no oponerse a que una cosa se haga".

Una mirada atenta a las definiciones arriba revelan la coincidencia en ellas de que "consentir" viene de consentire, o sea, estar de acuerdo, decidir de común acuerdo, conforme su origen filológico, su etimología: cum sentire. Esto pone de relieve el carácter individual y la voluntariedad que se deben hacer siempre presentes en el acto de consentir, so pena de invalidez del consentimiento. No por menos, señala MARTínEZ CUETO $^{11}$ que la libertad, además de la información y de la capacidad, son requisitos básicos de este proceso que ha de entenderse como el fruto de una relación clínica basada en dos pilares insustituibles: la información como proceso gradual más o menos complejo y la confianza.

El origen del término "consentimiento informado" remonta a la doctrina anglosajona, donde el concepto de informed consent -propiamente dicho-fue utilizado por primera vez en 1957 en California, Estados Unidos, en la sentencia de Salgo v. Stanford $^{12}$. En este caso, Martin Salgo, que padecía de insuficiencia vascular arterial en los miembros inferiores, fue sometido a una aortografía translumbar sin que fuera tomado su consentimiento, al final, se quedó parapléjico, lo que lo ha llevado a demandar el médico. Tal sentencia significó un hito fundamental en el proceso de introducción del

9 Vid. "Consentir", en REAL ACADEMIA ESPAÑOLA, Diccionario, apud SEOANE RODRÍGUEZ, J. A.: La esterilización: Derecho español y Derecho comparado. Madrid, Ed. Dykinson, 1998, p. 79.

${ }^{10}$ Vid. "Consentir", en SEÑAS: diccionario para la enseñanza de la lengua española para brasileños $/$ Universidad de Alcalá de Henares. Departamento de Filologia; tradução de Eduardo Brandão, Claudia Berliner. -2 $2^{a}$ ed.- São Paulo : Martins Fontes, 2001.

${ }^{11}$ MARTÍNEZ CUETO, P.: "Una perspectiva clínica acerca del consentimiento informado". Revista Galega de Actualidade Sanitaria, 2002, 1(4): 266-270.

${ }^{12}$ MARTÍNEZ CUETO, P.: "Una perspectiva clínica acerca del consentimiento informado". Revista Galega de Actualidade Sanitaria, 2002, 1(4): 266-270. 
deber de información como un deber legal estrechamente vinculado al deber de obtención del consentimiento, y no meramente un deber moral.

Con todo, se debe señalar que el primer caso judicial conocido sobre lo que más tarde de denominaría "consentimiento informado" no fue en realidad norteamericano sino británico, el caso Slater v. Baker \& Stapleton (1767), en lo cual el Sr. Slater denunció a los médicos Baker y Stapleton porque éstos estimaron que una fractura que éste tenía en una pierna no estaba bien curada y, así, pese a las protestas del paciente, no quitaron los vendajes que le habían colocado allí, fracturaran nuevamente la pierna y pusieran en ella un aparato ortopédico que habían inventado. Los médicos fueron condenados en una sentencia que usaba una argumentación similar a lo que más tarde de conocería por malpractice ${ }^{13}$.

En la literatura científica médica española, el término es citado por primera vez en 1930, pero es en 1972, con el Reglamento General de Gobierno y Servicio de las Instituciones Sanitarias de la Seguridad Social, cuando se establece que los enfermos tienen derecho a autorizar (directamente o a través de sus allegados) las intervenciones quirúrgicas y actuaciones terapéuticas que impliquen riesgo notorio previsible, así como a ser advertidos de su gravedad. Sin embargo, es a partir de la entrada en vigor de la Constitución española de 1978 cuando el concepto de consentimiento informado comienza a tener auténtico sentido e importancia, basado en la defensa que en ella se hace del libre desarrollo de la personalidad sobre la base de la libertad, del reconocimiento del derecho a la protección de la salud y de la edificación de los pedestales del derecho a la información. A partir de entonces, se produjo, en los años 80 y 90 , un afloramiento de la polémica sobre responsabilidad civil, específicamente sobre consentimiento informado. De hecho, PABlo Simón ${ }^{14}$ nos apunta cinco causas para que esto haya ocurrido: (a) la actitud menos pasiva del hombre moderno; (b) la tecnificación médica y la masificación; (c) la vulgarización de los saberes médicos; (d) la existencia generalizada de los seguros de responsabilidad civil; y (e) ciertas actitudes comerciales y de poca ética de los profesionales sanitarios.

Desde los artículos constitucionales en el tema del consentimiento informadoque de forma directa o refleja se configuran como el núcleo de la estructura jurídico sanitaria española ${ }^{15}$ - hasta el artículo 10 de la Ley 14/1986, de 25 de abril, General de Sanidad, se ha recorrido un largo camino. A la luz de los dictámenes constitucionales, se ha empezado a regular el derecho a la información y al consentimiento, de este

\footnotetext{
${ }^{13}$ Simón, P.: op. cit., pp. 50/54.

${ }^{14}$ Simón, P.: op. cit., p. 91.

${ }^{15}$ Martín Bernal, J. M.: Responsabilidad médica y derechos de los pacientes. Madrid, Ed. La Ley, 1998, p. 313.
} 
modo, ya en 1979 la Ley sobre extracción y transplante de órganos, de 27 de octubre, en su artículo $4^{\circ}$, trató del derecho a la información de los donantes.

Otro paso decisivo rumbo a la actual configuración fue la puesta en marcha, en 1984, por el Instituto Nacional de Salud (INSALUD), del plan de humanización de la atención sanitaria. Dicho plan tenía como objetivo la implantación de una carta de derechos del paciente y, en su punto cuarto, hacía referencia al derecho a la información: "el paciente o su representante tienen derecho a recibir información completa y continuada, verbal y escrita, de todo lo relativo a su proceso, incluyendo diagnóstico, alternativas de tratamiento y sus riesgos y pronóstico, que será facilitada en un lenguaje comprensible; en caso de que el paciente no quiera o no pueda manifiestamente recibir dicha información, ésta deberá proporcionarse a los familiares o persona legalmente responsable". Pasados dos años, la Ley 14/1986, General de Sanidad, recogió en el artículo 10.5: "que todos tienen derecho: a que se les dé en términos comprensibles, a él y a sus familiares o allegados, información completa y continuada, verbal y escrita, sobre su proceso, incluyendo diagnóstico, pronóstico y alternativas de tratamiento".

Hoy en día, se tiene que, en la normativa española, los marcos legales del consentimiento informado están consubstanciados en el Convenio relativo a los Derechos Humanos y la Biomedicina-firmado en el ámbito comunitario europeo-, de 4 de abril de 1997 (Convenio de Oviedo), y en la Ley 41/2002, de 14 de noviembre, Básica Reguladora de la Autonomía del Paciente y de Derechos y Obligaciones en Materia de Información y Documentación Clínica (LDP), la cual ha servido para adaptar la Ley General de Sanidad (14/1986) al contexto del llamado Convenio de Oviedo.

\section{EXCEPCIONES AL CONSENTIMIENTO INFORMADO}

El libre ejercicio de las libertades y de las garantías fundamentales está intrínsecamente ligado al Estado democrático de Derecho, lo cual debe servir, además de otras serventías, como garante de los derechos humanos, conforme propugna el preámbulo de la Magna Carta española. Con todo, este ejercicio no se da de manera absoluta, pues hay clara limitación a las voluntades particulares en pro del agrupamiento social. No obstante el ordenamiento jurídico reconozca como determinante, dentro de ciertos límites, la valoración subjetiva de los bienes jurídicos hecha por el particular, esto no supone aherrojar la voluntad del particular o infravalorar su libertad, sino la existencia de un interés de la comunidad en la preservación y protección de la salud de sus miembros frente a eventuales daños o menoscabos producidos por terceros, debido a que la salud, al igual que la vida, ocupa un lugar fundamental y fundamentante en el conjunto de bienes y valores vitales para la convivencia, pues constituye el presupuesto esencial y originario, el soporte del resto de valores y derechos de los que el hombre es 
portador ${ }^{16}$. Así que la franja de libertades personales se encuentra delimitada por la evaluación pública o social, ya que la integridad corporal, la libertad de movimientos, la propiedad, el honor y la esfera íntima se encuentran protegidos por la Constitución, al margen de la voluntad del titular, como bienes vitales de la comunidad que integran la libertad, la autodeterminación y la dignidad humana ${ }^{17}$. Por tanto, específicamente en se tratando de consentimiento informado, aunque objeto de muchas críticas, hay límites impuestos por ley al ejercicio del derecho a no consentir sobre determinado tratamiento.

En el plan español, las limitaciones al consentimiento se encuentran en la Ley General de Sanidad (Ley 14/1986), la cual traía en su cuerpo - en concreto en el artículo 10.6 - apenas tres supuestos de excepción al consentimiento informado: en el caso de que supusiera algún peligro para la salud pública, cuando el paciente esté discapacitado para tomar decisiones (en cuyo caso los familiares o allegados deberán decidir por él) y cuando la urgencia del caso no permita demoras, so riego de fallecimiento o de lesiones irreversibles. La Ley 41/2002, de 14 de noviembre, básica reguladora de la autonomía del paciente y de derechos y obligaciones en materia de información y documentación clínica, por su turno, buscando resguardar aun más el derecho a la autodeterminación del paciente y estar más acorde con las directrices del llamado Convenio de Oviedo, trae consigo las mismas previsiones de excepciones al derecho al consentimiento informado, pero con más restricciones, haciendo especial hincapié en que las mismas operan sólo respecto de las intervenciones clínicas indispensables a favor de la salud del paciente ${ }^{18}$. Dichas excepciones se encuentran descritas en el artículo 9.2, "a" y “b”, de la Ley 41/2002, siendo éstas:

a) Grave peligro para la salud pública;

b) Urgencia vital inmediata;

c) Supuestos en que el paciente no esté capacitado para tomar decisiones;

d) Menores de edad;

e) Renuncia y excepción terapéutica.

Los supuestos arriba enumerados, son, de hecho, los que se encuentran en el cuerpo de la normativa aplicable, pero se debe atentar que hay otros casos más de excepción al consentimiento informado, no previstos en la Ley 41/2002. La doctrina

16 Seone Rodríguez, J. A.: La esterilización: Derecho español y Derecho comparado. Madrid, Ed. Dykinson, 1998, p. 50.

17 Vid. Jescheck, H. H.: Tratado de Derecho Penal. Parte general. Trad. J.L. Manzanares Samaniego, Granada, Ed. Comares, 1993, pp. 337/338, apud Seonne RodríGuez, J. A.: op. cit., p. 75.

18 SÁnchez-CARo, J. et alli: Bioética, religión y derecho (actas del curso de verano de la Universidad Autónoma de Madrid celebrado en Miraflores de la Sierra del 14 al 16 de julio de 2005). Madrid, Ed. Fundación Universitaria Española, 2005, p. 24. 
nos aporta el llamado derecho a no recibir información-aunque haya opiniones a respecto de que éste sea más un supuesto de excepción, ya que se sustenta tratarse tan solamente de mera abdicación a la información previa, no importando la renuncia al derecho a ser informado propiamente en abdicarse al derecho a otorgar, o no, el consentimiento. Por su turno, la Ley General Penitenciaria de España nos trae más un supuesto de excepción al derecho al consentimiento informado. Como visto aquí, el derecho del paciente a aceptar o rechazar un tratamiento no es absoluto y encuentra varios límites, pero la discusión propuesta en este trabajo va a centrarse en la controversia que plantea el límite al derecho al consentimiento informado en el seno del sistema penitenciario español.

\section{F- EXCEPCIÓN AL CONSENTIMIENTO ESTIPULADA EN LA LEY GENERAL Penitenciaria de España}

Un supuesto de excepción al consentimiento informado, ampliamente discutido en la doctrina y en las decisiones judiciales, pero no previsto en la normativa que se refiere específicamente al consentimiento, nos presenta la Ley Orgánica 1/1979, de 26 de septiembre, General Penitenciaria, al establecer que "la Administración Pública carcelaria velará por la vida, integridad y salud de los internos" ${ }^{19}$. De acuerdo con el dispositivo legal al que se hace referencia, el Tribunal Constitucional de España ha fundamentado sus decisiones en los casos planteados por algunos presos del grupo GRAPO (SSTC 120/1990, de 27 de junio, 137/1990, de 19 de julio y la 11/1991, de 17 de enero), cuando en una huelga de hambre, llevada al límite y con grave peligro para las vidas de los encarcelados, fueron éstos sometidos a alimentación forzosa, aunque eso significase - al principio - una flagrante violación a sus derechos constitucionales a la dignidad personal, a la libertad, a la intimidad, a la vida y a la integridad física - como arguyeron los presos en recurso de amparo a las sentencias de la Audiencia Provincial de Madrid y de Guadalajara -, suprimiendo la toma de sus consentimientos en cuanto a la asistencia médica - procedimiento de alimentación forzosa - que recibieron sin que consintiesen. El Tribunal Constitucional (TC) consideró, en las decisiones apuntadas, la condición sui generis en que se encuentran los encarcelados, en especial la relación de sujeción que existe entre los presos y el Estado, a través de la Administración penitenciaria; el TC así analizó la situación de los encarcelados frente a la Administración carcelaria: "los reclusos se encontraban bajo una relación especial de sujeción que impone a la Administración la obligación de velar por la vida, integridad y salud de aquéllos permitiéndola, en determinadas

${ }^{19}$ Vid. art. 3.4 de la Ley Orgánica 1/1979, de 26 de septiembre, General Penitenciaria. 
situaciones, imponer limitaciones a los derechos fundamentales de internos que se colocan en peligro de muerte".

Otro argumento lanzado por el Tribunal Constitucional en los supuestos de las huelgas de hambre por parte de los presos es que la vida constituye el máximo valor a ser resguardado en cualquier ordenamiento jurídico constitucional y un supuesto ontológico sin el que los restantes derechos no tendrían existencia posible. Mucho criticado el segundo fundamento por cuenta del valor prevaleciente que el Tribunal otorga al derecho a la vida, ya que éste no se encuentra desvinculado de otro valores $\mathrm{y}$, además, que no existe de per se, $\mathrm{y}$, por consiguiente, se encuentra íntimamente vinculado a otros aspectos jurídicos y relacionado a las concepciones socioculturales y religiosas propias de cada uno, de cada sociedad, no se prestando a justificar la imposición de un tratamiento no consentido.

Entre los autores que han levantado voz contra los argumentos constantes de las sentencias del TC (SSTC) en los casos de limitaciones al derecho al consentimiento de los encarcelados está ATIENZA, que ha advertido que "si bien es cierto que si uno no está vivo no puede ejercer ningún derecho, ello no supone que de esta afirmación quepa deducir necesariamente que el derecho a la vida goza de preeminencia frente a cualquier otro derecho fundamental y que por ello ha de prevalecer" ${ }^{20}$. Siguiendo con las críticas al punto de vista dominante en el Tribunal Constitucional de España, el mismo doctrinador asevera que, como el encarcelamiento no permite que por sus propios medios los presos tengan acceso a los medios de salud, como haría cualquier otro ciudadano, establece la Ley Orgánica General Penitenciaria que es deber de la Administración velar por la vida, salud e integridad de los internos, es decir, esta obligación contemplada en la normativa penitenciaria implica el deber de la Administración de cubrir estas necesidades ordinarias y ofrecer, por tanto, las prestaciones sanitarias o alimentarias requeridas por las situaciones a que se enfrentan los internos, pero en modo alguno autorizaría para imponerlas en contra de la voluntad del interno, ni siquiera en aquellos casos extremos en los que el recluso haya perdido ya su estado de consciencia ${ }^{21}$.

Cumple señalar que en la propia STC 120/1990 hubo divergencia en cuanto a la limitación sui generis de los derechos fundamentos de los presos, asignada por el magistrado Miguel Rodríguez-PiñERo y Bravo-Ferrer, al decir que a su juicio "la obligación de la Administración penitenciaria de velar por la vida y la salud de los internos no puede ser entendida como justificativa del establecimiento de un límite adicional a los derechos fundamentales del penado, el cual en relación a su vida y salud

\footnotetext{
${ }^{20}$ Atienza, M.: Tras la justicia. Una introducción al Derecho y al razonamiento jurídico. Barcelona, Ed. Ariel, 1993, p. 102.

${ }^{21}$ Atienza, M.: op. cit., p. 97.
} 
y como enfermo, goza de los mismos derechos y libertades de cualquier otro ciudadano, y por ello ha de reconocérsele el mismo grado de voluntariedad en relación con la asistencia médica y sanitaria".

La evaluación del magistrado guarda consonancia con la guarida constitucional del derecho fundamental a la autonomía privada, consubstanciada en el amplío conjunto de "derechos y libertades" existente en el Capítulo Segundo del Título Primero de la Constitución de España, más específicamente en lo que dispone el artículo 10.1 de la Lex Mater española: "la dignidad de la persona, los derechos inviolables que le son inherentes, el libre desarrollo de la personalidad, el respeto a la ley y a los derechos de los demás son fundamento del orden político y de la paz social". De ahí, se ha afirmado que el principio de autonomía privada es un principio de Derecho, porque el respeto a la persona y su reconocimiento como ser de fines exigen su vigencia, y es dentro de su marco donde puede el hombre realizarse plenamente ${ }^{22}$, y más, que la supresión de la autonomía privada como principio general del Derecho llevaría consigo la total anulación de la persona y su conversión en puro instrumento de la comunidad ${ }^{23}$.

Las sentencias del Tribunal Constitucional en los casos de huelga de hambre de los encarcelados suenan merecedoras de reproche por la línea seguida, ya que privar los encarcelados del derecho a consentir, o no, con el procedimiento de alimentación por vía de sonda nasogástrica y, por consiguiente, negarles el derecho fundamental a la autonomía privada, significa una clara agresión a los dispositivos constitucionales españoles. Sin embargo, desde el ámbito comunitario nos llega el tenor de la sentencia emanada por el Tribunal Europeo en el Caso Pretty contra Reino Unido, de 29 de abril de 2002, la cual subraya que "la vida, como presupuesto del ejercicio de los demás derechos, constituye un derecho inderogable y, como tal, el margen de decisión personal no puede equivaler a una regla absoluta que exceptúe en todo caso el principio de irrenunciabilidad de los derechos fundamentales", lo que termina por reforzar la inclinación del TC español.

\section{(i. Conclusión}

Demasiada controversia se siguió a las decisiones del Tribunal Constitucional, pues para algunos sectores estaba clara la afronta a los dispositivos constitucionales garantizadores del derecho a la personalidad. Ajeno a las voces en contra, el TC mantiene su posición y, durante la huelga de hambre mantenida por un conocido preso etarra, más una vez se aplica la alimentación forzosa para alejar el riesgo de muerte, aunque que el recluso diera inequívocas señales de que querría seguir con su protesta hasta la muerte.

Por su parte, el gobierno de España sustentó que la decisión de ignorar el derecho del recluso a seguir con la huelga y a negarse a recibir alimentación por sonda nasogástrica 
fue correcta, porque la muerte del terrorista ciertamente desencadenaría una fuerte reacción de la banda terrorista ETA, significando un grave retroceso en el proceso de paz abierto en el año 2006, además de poner en riesgo la población. Con todo, una vez que el principio de autonomía fue elevado por la Constitución española a condición de fundamento del orden jurídico, se tiene que el principio general debe funcionar asimismo como criterio inspirador de toda labor interpretativa. Quiere ello decir que todas las normas jurídicas deberán interpretarse en la forma que resulte más conforme al principio general. Las que representen una excepción al principio de autonomía -normas prohibitivas, normas limitadoras-deberán interpretarse de manera restrictiva ${ }^{24}$. Pues, justamente ahí parece residir la equivocación de las decisiones del Tribunal Constitucional con respecto a los encarcelados, pues el texto de la Ley Orgánica 1/1979, de 26 de septiembre, General Penitenciaria, específicamente lo que dispone su artículo 3.4 al establecer que "la Administración Pública carcelaria velará por la vida, integridad y salud de los internos", no parece ser suficiente para fundamentar la restricción de los derechos de los reclusos, ya que en una interpretación restrictiva del dictamen, se puede vislumbrar allí tan solamente la obligación estatal de poner a disposición de los reclusos todos los medios para su curación, cabiendo, a posteriori, al preso decidir si acepta o no los tratamientos disponibles, después de recibir información clínica clara y suficiente. Así, parece más acertado que el ordenamiento jurídico español sea dotado de un dispositivo más claro y específico en cuanto a la restricción al derecho al consentimiento de los encarcelados, pues la solución por hora encontrada funciona, pero no da muestras de convencer.

\section{Bibliografia}

BRANDÃO, E.; BERLINER, C. SEÑAS: diccionario para la enseñanza de la lengua española para brasileños. São Paulo: Martins Fontes, 2001.

CANTERO MARTínEZ, J. La autonomía del paciente: del consentimiento informado al testamento vital. Albacete: Bomarzo, 2005.

Cerrillo, F. Nueva Enciclopedia Jurídica. t. V, Barcelona: Francisco Seix, 1985. Corbella Duch, J. Manual de Derecho sanitario. Barcelona: Atelier, 2006.

De Cossío y Corral, A. Instituciones de Derecho Civil. T. I, Madrid:. Civitas, 1988.

Guerrero Zaplana, J. El consentimiento informado. Su valoración en la jurisprudencia. Valladolid: Lex Nova, 2004.

Hattenhauer, H. Conceptos fundamentales del Derecho Civil. Trad. G. Hernández. Barcelona: Ariel, 1987.

Hоттогs, G. et alli. Nova enciclopedia de bioética. Santiago de Compostela: Servizo de Publicacións e Intercambio Científico, 2005. 
Martín Bernal, J. M. Responsabilidad médica y derechos de los pacientes. Madrid: La Ley, 1998.

Martínez Cueto, P. "Una perspectiva clínica acerca del consentimiento informado". Revista Galega de Actualidade Sanitaria, Vol. 1, nº 4, febrero de 2002.

SÁnChez CARO, J. “Autonomía y derecho a la salud: límites”. Revista Todo Hospital, $n^{\circ} 42$, diciembre de 1997.

SÁNCHEZ-CARO, J. "La relación médico-paciente en el siglo XXI" in Bioética, religión y derecho (actas del curso de verano de la Universidad Autónoma de Madrid celebrado en Miraflores de la Sierra del 14 al 16 de julio de 2005). Madrid: Fundación Universitaria Española, 2005.

SeoAne Rodríguez, J. A. La esterilización: Derecho español y Derecho comparado. Madrid: Dykinson, 1998.

SimÓN, P. El consentimiento informado. Historia, teoría y práctica. Madrid: Triacastela, 2000.

\section{EXCEÇÃO AO CONSENTIMENTO INFORMADO NA LEI PENITENCIÁRIA ESPANHOLA E AS INTERVENÇÕES MÉDICAS FORÇOSAS NAS GREVES DE FOME POR RECLUSOS}

Resumo: O presente estudo teórico tem por objetivo, ademais de esboçar um panorama sobre a figura jurídica do consentimento informado e de suas exceções, discutir a interpretação do Tribunal Constitucional espanhol da exceção ao consentimento prevista na Lei Penitenciária espanhola, especificamente nos casos de greves de fome levadas a cabo por presidiários acusados de terrorismo. A partir de revisão bibliográfica, analisou-se o teor das sentenças do TC espanhol, as quais, contrariando a regra geral que indica que se faz necessário o consentimento para que se aplique um procedimento médico, autorizam a alimentação forçosa de reclusos em risco de vida.

Palavras-chave: Consentimento informado. Greve. Fome. 


\title{
EXCEPTION TO INFORMED CONSENT IN SPANISH PENITENTIARY LAW AND MEDICAL FORCED INTERVENTION IN HUNGER STRIKES BY PRISONERS
}

\begin{abstract}
The present study aims to, moreover of sketching an overview on the juridical aspect of the informed consent and its exceptions, argue the interpretation of the Spanish Constitutional Court (TC) of the exception to the foreseen consent in the Spanish Penitentiary Law, specifically in the hunger strikes cases carried out by convicts accused of terrorism. Starting from a bibliographical revision, it analyzes the Spanish TC sentences content, which, thwarting the general rule that imposes prior consent for medical procedures, they authorize mandatory feeding of prisoners in risk of death.
\end{abstract}

Key words: Informed consent. Strike. Hunger. 